\title{
THE USE OF BILATERAL DEEP INFERIOR EPIGASTRIC PERFORATOR FLAP (DIEP) IN BUTTOCK DEFORMITY RECONSTRUCTION - CASE REPORT
}

\author{
Vu Ngoc Lam*, Nguyen Quang Duc*, Le Diep Linh*, Nguyen Phuong Tien*
}

\section{ABSTRACT}

Abstract: Buttock soft tissue defects can be encountered due to many causes and also have many treatment solutions. Usually, defects are common on one side of the buttocks and cutaneous skin flaps in place, local or regional used. The article analyzes a rather rare case with a soft tissue defect in the buttocks on both sides as a necrotic sequela after injecting fillers for cosmetic purposes. After treatment of necrotizing inflammation, the sequelae left behind is a concave scar and deformed buttock on both sides. The local fat flaps are not valuable in this case, while the free fat flap will face many risks of failure due to the use of 2 flaps on both sides, the post-operative care position is also very difficult, easy to cause tension, compress the vascular pedicles. This clinical case with the use of bilateral DIEP flaps, and the postoperative results in this case are analyzed and evaluated in the article.

Keywords: DIEP flap, buttock necrosis

\section{INTRODUCTION}

The large soft tissue defect in the buttocks area has little effect on function, but greatly affects the aesthetics and quality of life of the patient. Some methods of reconstruction for soft tissue defects such as local flaps, autologous fat injection... may be valuable in case of small defects, on one side. With large defects, on both sides of the buttocks, it is not easy to find materials and effective surgical

\footnotetext{
* 108 Military Central Hospital

Responsible person: Vu Ngoc Lam

Email: vungoclamb8@gmail.com

Date of receipt: $31 / 5 / 2021$

Date of scientific judgment: 25/6/2021

Reviewed date: 01/8/2021
}

methods. Some flaps such as anterior lateral thigh flap, scapular-parascapular flap, latissimus dosi flap... can be used, but it will be very complicated and risky if using a free flap for both sides of the buttock, Moreover, there would be many functional and aesthetic effects in the donor area for using these flaps. Deep Inferior Epigastric Perforator Flap (DIEP) is known to be a very valuable material in plastic surgery with large volume, stable vascular pedicle, little influence on regional function. There have been many studies and reports on the use of DIEP flaps in breast reconstruction after mastectomy for breast cancer in the form of a free style, but in the form of an pedicle flap, there are not many applications. We present a case of using bilateral pedicle DIEP flaps to reconstruct soft tissue deformities on both sides of the buttocks and analyze some factors on indications, techniques, and surgical results.

\section{CASE REPORT}

- History: A 40 year - old female patient. She had the buttocks augmentation with filler injection. After 1 week of injection, complication happened with high fever and swelling, redness, pain in the buttocks, then necrosis of the entire skin and subcutaneous tissue in the buttocks on both sides. She was taken to the hospital for surgical treatment of necrosis debrided, VAC at the lesion until the good granuloma spread over the wound and then split skin graft took over. 
After healing, there were big deformities with concaved scars of the buttocks and hips on both sides with the size of $15 \times 17 \mathrm{~cm}$.
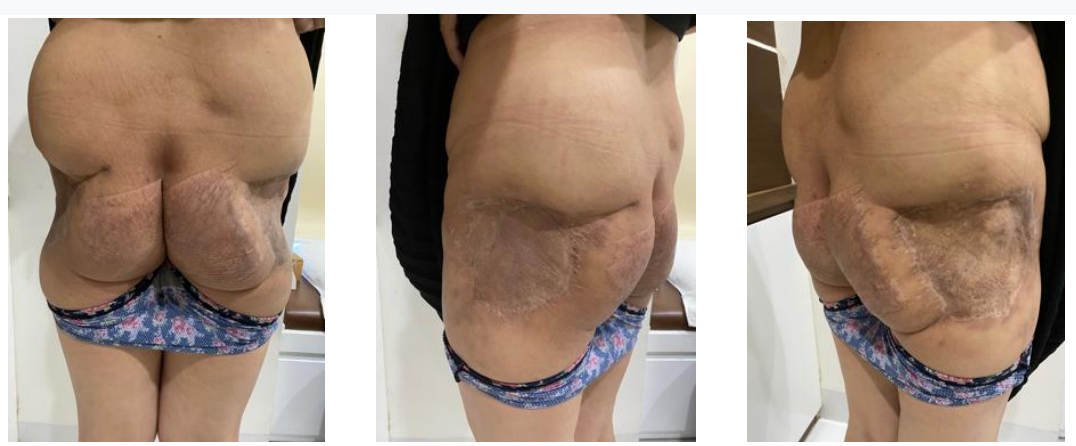

Pictures 1-2-3: The deformities of the buttocks

- Abdominal examination: The patient had given birth twice by cesarean section and there was a $15 \mathrm{~cm}$ long, soft horizontal scar, her belly moderate excess fatty skin. Doppler ultrasound examination clearly shows the deep inferior epigastric artery on both sides, with 4-5 perforators on each side of the flap, about $3-4 \mathrm{~cm}$ far from the midline.

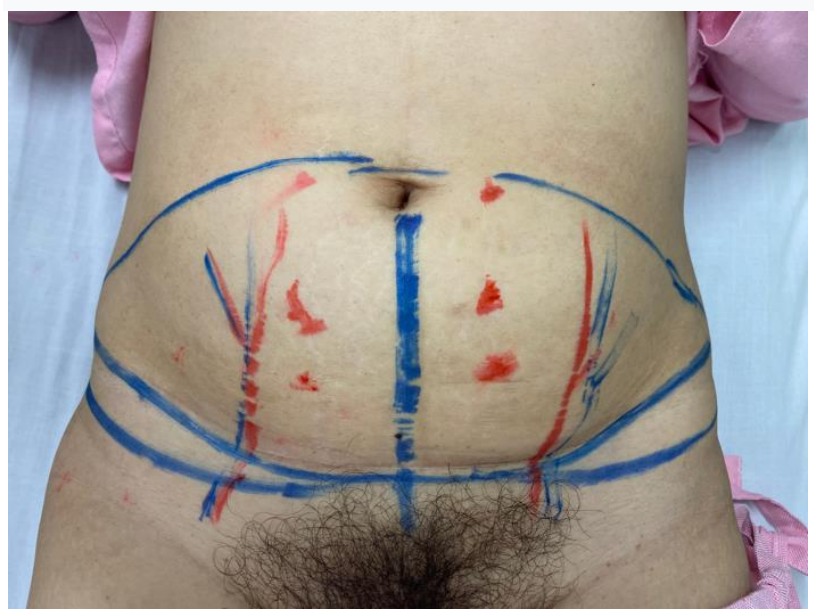

Pictues 4: DIEP flap design
- The operation: the DIEP flap designed with all the fatty skin of the abdomen below the umbilicus, divided into 2 flaps (Picture 4) The DIEP flap was dissected with 3 perforators for each side, the deep epigastric pedicle was maximally dissected to the origin of the superficial iliac artery, the pedicle was $12 \mathrm{~cm}$ long, including 1 artery and 1 concomitant vein.(Picture 5)

We did not create a tunnel, but cut the skin between the flap donor area and the flap receiving area to move the flap to avoid high tension and compression of the vascular pedicle of the flap. (Picture 6) 


\section{VIETNAM MEDIGAL JOURNAL No1\&2/2021}

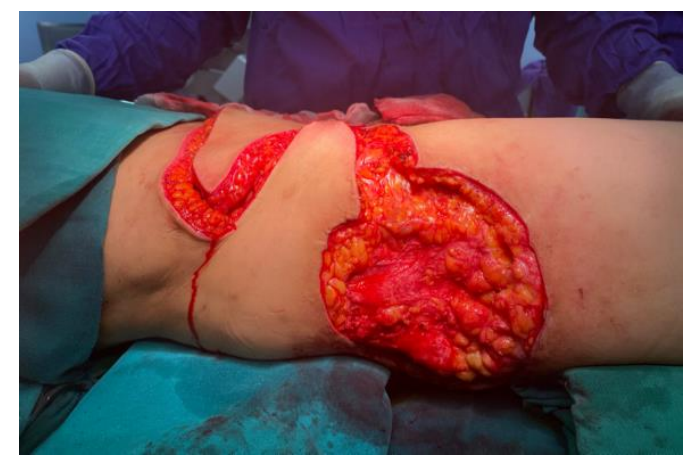

Picture 6: The defect after scar removed

The flap is moved to the buttocks with attached pedicle, the abdomen is dissected and closed directly.
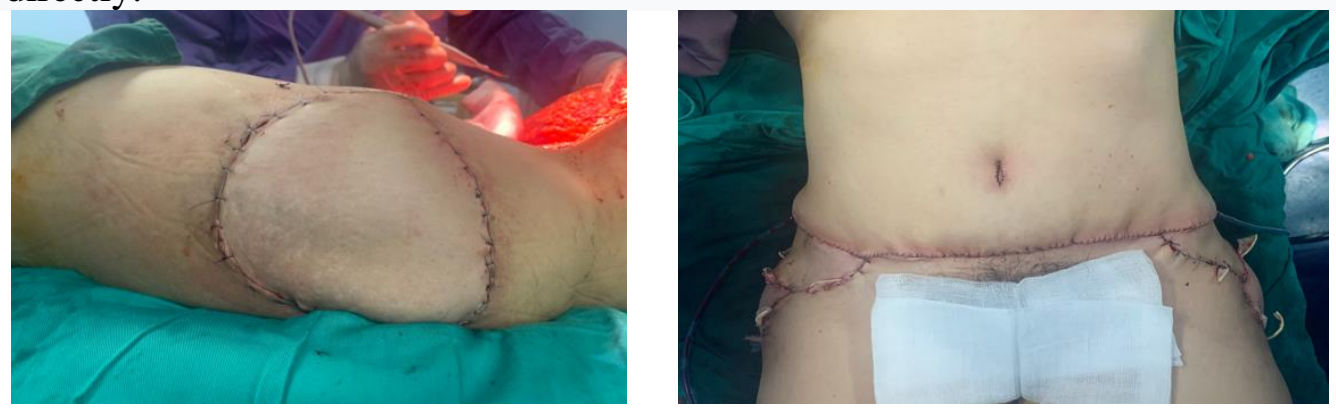

Pictures 7-8: The flap emplaced and abdominal feature after the operation completed

- Post operation: The wounds primary healed, the patient was discharged after 2 weeks
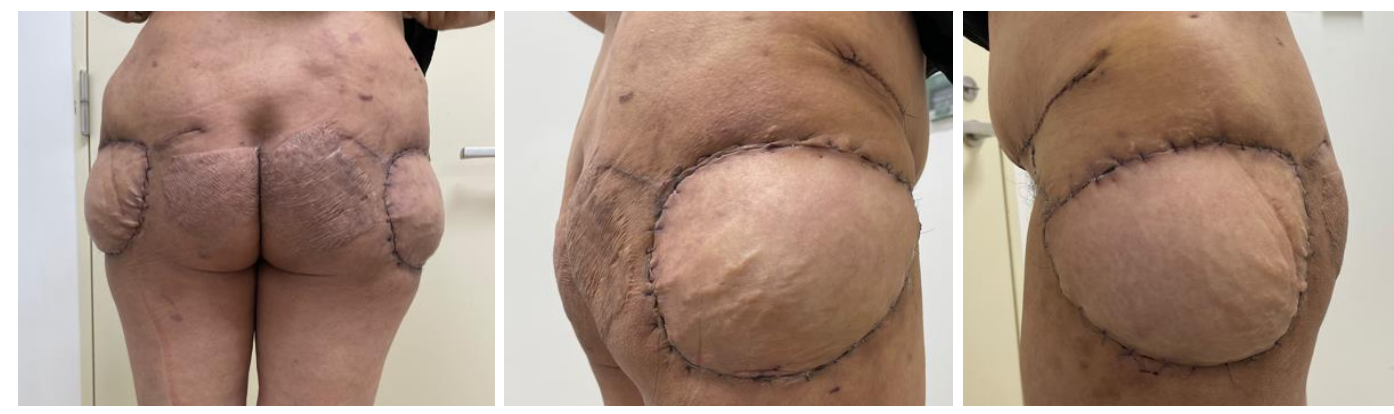

Pictures 9-10-11: The flaps after 10 days

After 3 months, the skin flap is match with the skin around, the function of the buttocks and abdomen is completely normal, the patient is very satisfied with the surgical results.
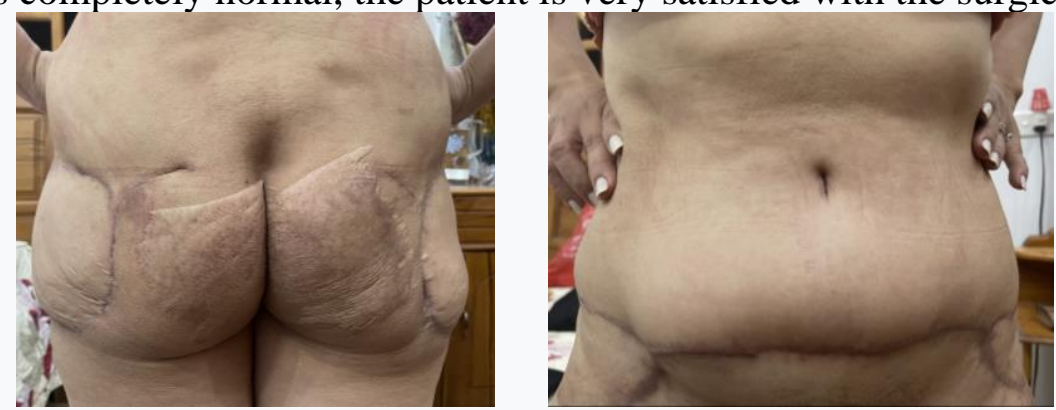

Pictures 12-13: The result after 3 months 


\section{DISCUSSION \\ 3.1. About soft tissue defects in the buttocks area}

In the literature, there are many reports of soft tissue defects in the buttocks, but the main cause is mainly due to pressure ulcers in the sacrum or bilateral hips due to patients lying for a long time with diabetes, paralysis...Buttock necrosis due to filler injection is a rare complication, especially large area necrosis, on both sides of the buttocks. In Vietnam recently, due to the trend of abusing filler injection for anesthetic purpose, there are many complications due to injections of fillers that do not meet quality standards as well as incorrect injection techniques. This patient was injected with about $300 \mathrm{cc}$ of liquid silicone into the buttocks on both sides, after the injection caused abscess necrosis of the entire skin and subcutaneous fat tissue in the superiorlateral buttock and hips on both sides. The treatment to heal the wound from removing the abscesses, debris the necrosis, cleaning the lesion basement for split skin grafting. The treatment lasted about 2 months with many surgical interventions. The defect areas with size $12-15 \mathrm{~cm}$ were very large compared to the size of buttock lesions in some studies of other authors. Sorensen JL. described a study showing the size of the median defects were approximately $5 \times 6 \quad \mathrm{~cm}^{2}$ and $8 \times 9$ $\mathrm{cm}^{2}$. [1]

\subsection{About the indication of flaps}

Most of soft tissue defects in the buttock area due to sacroiliac ulcers, the use of local fascial flaps is the most effective, safe and easiest solution. Cutaneous flaps with superior or inferior gluteal artery pedicle or random flaps have been reported by many authors [2.3.4]
Rubayi S, Chandrasekhar BS showing a study of using local flaps for treatment of sacral ulcer with good results. [2]. However, in this case local flaps could not be used because the defect was too large and bilateral. Microsurgery flaps may be the solution, however, if microsurgery is used, it is necessary to anastomose both 2 pedicles to the recipient's vessels. For the receiving area, the most suitable vessel is the superior gluteal vessel, however, with extensive inflammatory lesions and many previous surgical interventions, the superior gluteal vascular bundle is likely already damaged. Moreover, the sequelae of flap removal in the dorsal or thigh area greatly affect the function and especially the aesthetics for female patients. Therefore, microsurgical flap is not the preferred solution in this case.

The DIEP flap is the flap with the most advantages with a large volume for defects, the flap site is very favorable for women who have given birth who often have a lot of skin and excess fat [5,6]. However, if we have to do a microsurgery flap, it will also be very difficult because you have to use both flaps at the same time to connect to the upper buttock vein so we had to consider to use the flap in the form of a pedicle, which greatly simplifies the technique, increases the level of safety and reduces the risk.

\subsection{About the technique of using flaps}

An overview research of using DIEP revealed that the risk of total flap loss was six times greater in bilateral reconstruction (RR 6.4, 95\% CI 1.6-26, $\mathrm{p}=0.011)$. Both unilateral and bilateral DIEP flap breast reconstructions are safe, with a low risk of complications; however, bilateral reconstruction was associated with a higher risk of complications and total flap loss.[7,8,9] 
Here we use bilateral DIEP flaps with 2 separate pedicles, and without tunneling the flap from the area to the receiving area, we have to cut the skin, remove the subcutaneous fat to avoid stretching the vascular pedicle.

\section{CONCLUSION}

Major defects in the buttock region on both sides, sequelae of tissue necrosis after filler injection are rare, and there are not many suitable options to create a shape to cover the defect. The pedicle DIEP flap is the preferred choice with many advantages: The volume and quality of the tissue is completely suitable for the buttock defect, the flap has a constant supply of blood, the length of the vascular pedicle is suitable for transferring the flap to the buttock area, the flap donor area ensures good functionality and aesthetics.

\section{REFERENCES}

1. Bauer JD, Mancoll JS, Phillips LG. Pressure sores. In: Thorne CH, Beasley RW, Aston SJ, Bartlett SP, Gurtner GC, Spear SL, editors. Grabb and Smith's Plastic Surgery. Philadelphia, PA: Lippincott Williams \& Wilkins; 2006. pp. 722-9.

2. Rubayi S, Chandrasekhar BS. Trunk, abdomen, and pressure sore reconstruction. Plast Reconstr Surg. 2011;128:201e-15e. [PubMed] [Google Scholar]

3. Sorensen JL, Jorgensen B, Gottrup F. Surgical treatment of pressure ulcers. Am J
Surg. 2004;188:42-51. [PubMed] [Google Scholar]

4. Yamamoto Y, Ohura T, Shintomi T, Sugihara T, Nohira K, Igawa H. Superiority of the fasciocutaneous flap in reconstruction of sacral pressure sores. Ann Plast Surg. 1993;30:116-21. [PubMed] [Google Scholar]

5. Corrine Wong, M.R.C.S. Michel Saint-Cyr, M.D. Ali Mojallal, M.D. Tim Schaub, M.D. Steven H. Bailey, M.D. Simon Myers, Ph.D., F.R.C.S. Spencer Brown, Ph.D. Rod J. Rohrich, M.D (2010), "Perforasomes of the DIEP Flap: Vascular Anatomy of the Lateral versus Medial Row Perforators and Clinical Implications" Volume 125, Number 3 - Perforasomes of the DIEP Flap, Plastic and Reconstructive Surgery $\bullet$ March 2010

6. Feller AM, Galla T (1998), "The deep inferior epigastric perforator free flap", Clin Plast Surg; 25; 197-206.

7. Kosima I,Soeda $S$ (1989), "Inferior epigastric artery skin flap with out rectus abdominis muscle", Br J Plast Surg; 42:645-648.

8. W. Bradford Rockwell, Craig A. Hurst, David A. Morton (2006), "The Deep Inferior Epigastric Artery:Anatomy and Applicability as a source of Microvascular Graft", Plast. Reconst. Surg; 120(1): 209-213.

9. Mark Schaverien, M.R.C.S. Michel SaintCyr, M.D. Gary Arbique, Ph.D. Spencer A. Brown, Ph.D (2008). "Arterial and Venous Anatomies of the Deep Inferior Epigastric Perforator and Superficial Inferior Epigastric Artery Flaps." Plastic and Reconstructive Surgery • June 2008. Volume 121, Number 6 - Anatomy of DIEP and SIEA Flaps 